\title{
Source, fate and budget of Dechlorane Plus (DP) in a typical semi- closed sea, China ${ }^{\text {is }}$
}

\author{
Xiaomei Zhen ${ }^{\text {a, b, c }}$, Yanfang Li ${ }^{\text {b }}$, Xinming Wang a , Lin Liu ${ }^{\text {a, b, c }, \text { Yanan Li }}{ }^{\text {b, c }}$, \\ Chongguo Tian ${ }^{\mathrm{b}}$, Xiaohui Pan ${ }^{\mathrm{b}}$, Yin Fang ${ }^{\mathrm{e}}$, Jianhui Tang ${ }^{\mathrm{b}, \mathrm{d},{ }^{*}}$ \\ a State Key Laboratory of Organic Geochemistry, Guangzhou Institute of Geochemistry, Chinese Academy of Sciences (CAS), Guangzhou, 510640, China \\ ${ }^{\mathrm{b}}$ CAS Key Laboratory of Coastal Environmental Processes and Ecological Remediation, Shandong Key Laboratory of Coastal Environmental Process, Yantai \\ Institute of Coastal Zone Research, Chinese Academy of Sciences, Yantai, 264003, China \\ ${ }^{\mathrm{c}}$ University of Chinese Academy of Sciences, Beijing, 100049, China \\ ' Center for Ocean Mega-Science, Chinese Academy of Sciences, Qingdao, 266071, China \\ e College of Marine Ecology and Environment, Shanghai Ocean University, Shanghai, 200306, China
}

\section{A R T I C L E I N F O}

\section{Article history:}

Received 10 September 2020

Received in revised form

28 November 2020

Accepted 1 December 2020

Available online 3 December 2020

\section{Keywords:}

Dechlorane plus

DP

Bohai sea

Budget

Multi-box mass balance

\begin{abstract}
a b s t r a c t
Dechlorane Plus (DP), which has severe effects on marine ecosystems, has been proposed for listing under the Stockholm Convention as a persistent organic pollutant (POPs). This study was the first comprehensive investigation of the concentration and fate of DP in the Bohai Sea (BS) based on determination of river estuary water, river estuary sediment, surface seawater, bottom seawater, and sea sediments samples. The highest water DP levels were found in river estuary in Tianjin in North China due to the huge usage of DP in recent years, and spatial distribution analysis indicates it was mainly affected by regional high urbanization and emission of E-waste. The spatial distribution of DP in the BS was mainly affected by a combination of coastal hydrodynamics and land anthropogenic activities. On the basis of multi-box mass balance, simulations of DP in seawater showed an increase from 2014 to 2025, before leveling off at $184 \mathrm{pg} \mathrm{L}^{-1}$ by a constant DP input to the BS. Riverine discharge almost contributed to the total input ( $\sim 99 \%)$ and dominated the DP levels in the BS. Degradation of DP accounted for $55.3 \%$ and $78.1 \%$ of total DP output in seawater and sediment, respectively, indicating that degradation mainly affected decline of DP in the environment.
\end{abstract}

() 2020 Elsevier Ltd. All rights reserved.

\section{Contribution of the authors}

Xiaomei Zhen, Conceptualization; Investigation; Methodology; Writing - original draft; Yanfang Li, Investigation; Methodology; Xinming Wang, Funding acquisition; Project administration; Resources; Supervision; Writing - review \& editing, Lin Liu, Investigation; Yanan Li, Investigation; Chongguo Tian, Methodology. Xiaohui Pan, Methodology. Yin Fang: Methodology. Jianhui Tang, Conceptualization; Funding acquisition; Project administration; Resources; Supervision; Writing - review \& editing.

\footnotetext{
This paper has been recommended for acceptance by Pavlos Kassomenos.

* Corresponding author. CAS Key Laboratory of Coastal Environmental Processes and Ecological Remediation; Shandong Provincial Key Laboratory of Coastal Environmental Process, Yantai Institute of Coastal Zone Research, Chinese Academy of Sciences, Yantai, 264003, China.

E-mail address: jhtang@yic.ac.cn (J. Tang).
}

\section{Introduction}

Dechlorane Plus (DP), a replacement for decabromodiphenyl ether (Deca-BDE), comprises two major stereoisomers (syn-DP and anti-DP) in commercial mixture, and has been widely used in plastic materials, computer connectors, electrical wires, and cable coatings (Wang et al., 2017b; Zhou et al., 2017). The annual productions of DP by OxyChem (USA) and Anpo Electrochemical Co. (China) are $~ 5000$ and 300-1000 ton, respectively (Wang et al., 2017b). Previous studies had reported that DP had been widely detected in biota, human, air, soil, water, and sediment (Abdel Malak et al., 2018; Chen et al., 2018; Moller et al., 2011; Wang et al., 2010a). Moller et al. (2010) detected airborne DP in a remote area, suggesting that it has long-range atmospheric transport potential. In addition, DP is also accumulated and biomagnified in humans and other organisms (Abdel Malak et al., 2018; Qiao et al., 2018). Thus, DP has properties similar to those of persistent organic pollutants (POPs) and it has been considered as a candidate for Annex 
D evaluation under the Stockholm Convention on POPs (Sun et al., 2016). With the phasing out of polybrominated diphenyl ether (PBDEs), DP have become an alternative resource for electronic and electrical applications, and hence is now being released into the environment unintentionally.

Coastal seas are important transition zone for the buffering of organic contaminants from the land to the ocean. Terrestrial inputs, including riverine inputs, greatly impact the distributions and fates of DP in coastal seas (Wang et al., 2016a). After being released into the environment, DP is likely absorbed onto fine particles and then be deposited onto the sediment owing to its high log $\mathrm{K}_{\mathrm{OW}}$ value (9.3) (Fang et al., 2014). Thus, marginal and open seas are regarded as an important reservoir for DP (Jia et al., 2011; Zhao et al., 2011). Recently, several studies had focused on investigating the concentration and distribution of DP in the environment (He et al., 2014; Zhou et al., 2017; Zhu et al., 2018), but little attention has been paid to an extensive and comprehensive understanding of DP concentrations, fluxes, and budgets in coastal seas. The multi-box mass balance model can be used to predict the fate of POPs in the environment and to gain an appreciation of the relative importance of various fate processes (Mackay et al., 1994). The model had been applied to perfluorooctanoic acid (PFOA) and polychlorinated biphenyls (PCBs) in bays and lakes, respectively (Mackay et al., 1994; Sanchez-Soberon et al., 2020), and could provide a new perspective on the fate interpretation of DP.

China, with a domestic production volume of 300 ton for DP in 2006, is considered as a large manufacturer and consumer of halogenated flame retardants (HFRs), reflecting the rapid growth in its electrical and electronic industries (Zhu et al., 2018). The Bohai Sea (BS) is a shallow semi-closed marginal sea that is strongly impacted by the industrialized and urbanized Liaoning, Hebei, and Shandong provinces, and by the Beijing-Tianjin metropolitan area (Fig. 1). The BS coastal area represents a major economic engine of China, accounting of one fourth of the gross domestic product and hosting six of the top 10 busiest ports in China in 2018 in terms of cargo throughput. Thirteen mega cities are scattered around the BS, and more than 100 rivers discharge into it. The area and average depth of the BS are77,000 $\mathrm{km}^{2}$ and $18 \mathrm{~m}$, respectively. Previous study had reported that marginal sea accounted for more than $80 \%$ of global organic carbon deposition in the sea (Liu et al., 2018). Thus, the BS is not only a retaining area but also an important sink for DP.

The present study investigated DP concentrations in river water, surface seawater, bottom seawater, river sediment, and sea sediment samples from the BS and part of the northern Yellow Sea (NYS). The main objectives were (a) to discuss DP levels and the spatial distribution of DP and its impact factors in the BS; (b) to explore the differences in $f_{\text {syn }}$ (syn-DP/(anti-DP + syn-DP) values among the different media; and (c) to estimate time-dependent concentrations and budgets of DP using a multi-box mass balance model in the BS.

\section{Methods and materials}

\subsection{Sampling methods}

Water samples ( $20 \mathrm{~L})$ were collected and stored in stainlesssteel barrels, and filtered with a peristaltic pump through glass fiber filters (GFF, $150 \mathrm{~mm}, 0.7 \mu \mathrm{m}$ pore size) for water particulate phase combined in series with a glass column packed with Amberlite ${ }^{\circledR} X A D-2$ for water dissolved phase. All GFF filters had been previously combusted at $450{ }^{\circ} \mathrm{C}$ for $5 \mathrm{~h}$ and the XAD column had been cleaned with high pure methanol and dichloromethane (each for $24 \mathrm{~h}$ by Soxhlet extraction) prior to use. A total of 135 water samples were collected from September 2013 to December 2014, including 33 fresh water samples from rivers emptying into the BS, 67 surface seawater samples collected from the BS and NYS, and 35 bottom seawater samples collected from the BS and NYS (Fig. 1). It is worth noting that there were 11 river columns broken during the experiment. Hence, there were 135 and 124 samples for filters and columns, respectively. Columns were stored at under $4{ }^{\circ} \mathrm{C}$ and filters under $-20^{\circ} \mathrm{C}$ until analysis. All water samples were filtered on board within $8 \mathrm{~h}$ of sampling.

Sediment samples were collected using a stainless-steel box corer or grab sample. From 2013 to 2014, a total of 35 sediment samples including 32 rivers emptying into the BS and three rivers emptying into the NYS, and 96 surface sediment samples including 84 from the BS and 12 from the NYS (Fig. 1) were collected. Sediment samples were wrapped in pre-combusted aluminum foils,

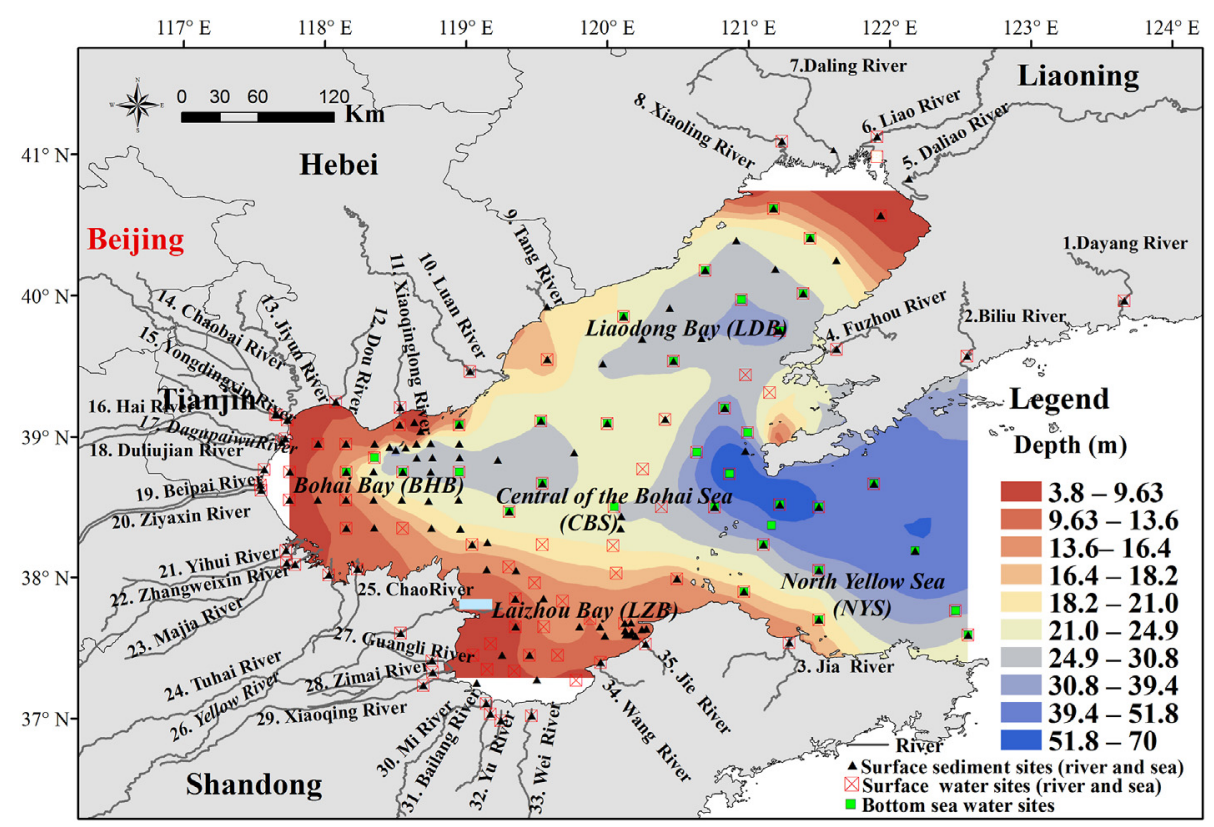

Fig. 1. Map shows the sampling stations for river and marine samples in the BS (the number before each river name denoted to the corresponding river). 
kept in polyethylene bags, and stored at $-20^{\circ} \mathrm{C}$ until analysis.

\subsection{Sample extraction and analysis}

Before extraction, sediment, filters, and columns were all spiked with $10 \mathrm{ng}$ of ${ }^{13} \mathrm{C}$-HBB (Cambridge Isotope Laboratories) and $20 \mathrm{ng}$ of PCB 209 (AccuStandard) as surrogate standards. The sample analysis procedure was based on previous studies (Moller et al., 2011; Zhen et al., 2016, 2018). Briefly, sediments and filters were Soxhlet extracted for $\sim 24 \mathrm{~h}$. Columns were extracted in a modified Soxhlet apparatus for $\sim 24 \mathrm{~h}$. Dichloromethane (DCM) was used for the sediment, filters, and columns extraction. Extracts of all samples were concentrated to $\sim 1 \mathrm{~mL}$ in a rotary evaporator and then transferred to hexane (HEX). All samples were cleaned using a column filled with $2 \mathrm{~g}$ of anhydrous sodium sulfate topped with $2.5 \mathrm{~g}$ of $10 \%$ water deactivated silica gel (80-100 mesh) and $1 \mathrm{~g}$ of anhydrous sodium sulfate. After cleaning, the eluent was further concentrated to $100 \mu \mathrm{L}$ in HEX under a gentle $\mathrm{N}_{2}$ stream. Finally, $20 \mathrm{~g}$ PCB 208 was added before the samples for instrument analysis and serve as an injection standard to correct injection variation during sample analysis.

syn-DP and anti-DP (AccuStandard) were measured via an Agilent 7890A gas chromatograph and an Agilent 5975C mass spectrometer in the electron capture negative ionization mode. DB-5HT (15 $\mathrm{m} \times 0.25 \mathrm{~mm} \times 0.1 \mu \mathrm{m}$, J\&W GC column, Agilent) was used for separation of syn-DP and anti-DP. The column temperature program started at $80{ }^{\circ} \mathrm{C}$ and was maintained for $2 \mathrm{~min}$; then it was ramped up to $200{ }^{\circ} \mathrm{C}$ at $10{ }^{\circ} \mathrm{C} \mathrm{min}-1$ and maintained for $5 \mathrm{~min}$. Further, the temperature was increased to $260{ }^{\circ} \mathrm{C}$ at $10{ }^{\circ} \mathrm{C} \mathrm{min}-1$ and maintained for $5 \mathrm{~min}$; finally, it was increased to $310^{\circ} \mathrm{C}$ at $5^{\circ} \mathrm{C}$ $\mathrm{min}^{-1}$ and holding for $5 \mathrm{~min}$ (Zhen et al., 2016, 2018). The injector and MS transfer line temperatures were $280{ }^{\circ} \mathrm{C}$ and $310{ }^{\circ} \mathrm{C}$, respectively.

\subsection{Quality assurance and quality control}

Solvents including HEX and acetone (ACE) were of gas chromatography grade (Merck, KGaA) and DCM used was redistilled. In addition, all glassware and anhydrous sodium sulfate were baked at $450{ }^{\circ} \mathrm{C}$ for $5 \mathrm{~h}$ prior to use. There are three field blanks of filters and two field blanks of XAD columns were collected in present study (Table S1). Besides, there are 20 lab blanks of sediments processed in present study (Table S1). Method detection limits (MDL) were calculated by adding the mean to thrice the standard deviation for the filed (lab) blank samples. The MDLs of syn-DP for filters, XAD columns, and sediments were $1.05 \mathrm{pg} \mathrm{L}^{-1}, 26.3 \mathrm{pg} \mathrm{L}^{-1}$, and $0.80 \mathrm{pg} \mathrm{g}^{-1} \mathrm{dw}^{-1}$, respectively. Besides, The MDLs of anti-DP for filters, XAD columns, and sediments were $1.29 \mathrm{pg} \mathrm{L}^{-1}, 28.5 \mathrm{pg} \mathrm{L}^{-1}$, and $3.41 \mathrm{pg} \mathrm{g}^{-1} \mathrm{dw}$, respectively. The mean surrogate recoveries from filters were $109 \% \pm 44.7 \%$ for ${ }^{13} \mathrm{C}-\mathrm{HBB}$ and $106 \% \pm 44.3 \%$ for PCB 209. For columns, the mean recoveries were $92.3 \% \pm 32.7 \%$ for ${ }^{13} \mathrm{C}-\mathrm{HBB}$ and $87.7 \% \pm 29.1 \%$ for PCB 209 . For sediment samples, the mean recoveries were $74.8 \% \pm 47.7 \%$ for ${ }^{13} \mathrm{C}-\mathrm{HBB}$ and $73.1 \% \pm 43.9 \%$ for PCB 209. Owing to the high recovery rate and low blank values, DP concentrations were not recovery corrected. If DP concentrations were lower than their MDL (method detection limit), they were denoted as 'n.d.'. Measured grain-size distributions for sediments in the BS were consistent with those obtained in a previous study (Fang et al., 2015a). Besides, concentrations of particulate organic carbon (POC) of river water, surface seawater, and bottom seawater were measured in previous study, data of which was obtained from Huang (2016). Suspended particulate matter concentrations were measured in this study and Figure S1b displayed that the surface SPM concentrations in the BS. Total organic carbon (TOC) in all river sediment was measured in our previous work
(Wang et al., 2015).

\subsection{Calculation of river flux in the $B S$}

Generally, DP contamination in BS samples was severely affected by riverine inputs. Among the 35 rivers considered in the present study, 30 discharged into the BS. The river campaign was carried out over one summer, so the DP input (DP input; $\mathrm{kg}_{\text {year }}{ }^{-1}$ $\left(\mathrm{yr}^{-1}\right)$ ) was estimated by the following equation (1) (Wang et al., 2015):

$\mathrm{DP}_{\text {input }}=10^{-12} \times \mathrm{Q}_{\mathrm{i}} \times \mathrm{C}_{\mathrm{DP}}$

Where DP input is the riverine input of DP; $Q_{i}$ is the annual runoff $\left(\mathrm{m}^{3}\right)$, which was obtained from Wang et al. (2015) and references therein (Table S2); and $\mathrm{C}_{\mathrm{DP}}$ is the determined water DP concentration $\left(\mathrm{pg} \mathrm{L}^{-1}\right)$.

\subsection{Multi-box mass balance model}

The multi-box mass balance model can treat the BS as an independent box with two homogeneously mixed compartments (water and sediment). The model was developed by Mackay et al. (1994), had been used to assess the relative importance of various fate processes, and estimate the temporal responses of seas and lakes to loading reduction. In the mass balance theorem, all processes can be determined from the following equations:

$$
\begin{aligned}
& \mathrm{dM}_{\mathrm{W}} / \mathrm{dt}=\mathrm{E}_{\mathrm{R}}+\mathrm{E}_{\mathrm{A}}+\mathrm{M}_{\mathrm{S}} \times \mathrm{K}_{5}-\mathrm{M}_{\mathrm{W}} \times\left(\mathrm{K}_{1}+\mathrm{K}_{2}+\mathrm{K}_{3}+\mathrm{K}_{4}\right) \\
& \frac{\mathrm{dM}_{\mathrm{W}}}{\mathrm{dt}}=\mathrm{M}_{\mathrm{W}}-\mathrm{M}_{\mathrm{S}} \times\left(K_{5}+K_{6}+K_{7}\right)
\end{aligned}
$$

Here, $\mathrm{M}_{\mathrm{W}}$ and $\mathrm{M}_{\mathrm{S}}$ are the mass (pg) of DP in water and sediment, respectively; $t$ is the time [day $\left(d^{-1}\right)$ ] for the two equations; $E_{R}$ represents the total discharge of compounds to the BS from rivers; and $E_{A}$ represents three processes of deposition from the air (atmospheric dry deposition, atmospheric wet deposition, and absorption from atmosphere), and data of DP concentration in atmosphere in the BS was obtained from our previous work (Liu et al., 2020). The values of $E_{R}$ and $E_{A}$ were listed in Table $S 2$ and Table S3, respectively. Detail equations of calculation of $K_{1}, K_{2}, K_{3}$, $\mathrm{K}_{4}, \mathrm{~K}_{5}, \mathrm{~K}_{6}$, and $\mathrm{K}_{7}$ was described in supporting information (SI) 1.1. Values of $K_{1}, K_{2}, K_{3}, K_{4}, K_{5}, K_{6}$, and $K_{7}$ and all parameters used in present study were summarized in Table S4 and Table S4-1, respectively.

\section{Results and discussion}

\subsection{DP concentrations and comparison}

For water samples including river and marine water samples, DP were both analyzed in dissolved phase and particulate phase. DP were all detected in dissolved phase, concentrations of which accounted less than $3.6 \%$ of the total DP concentrations in river water. Besides, the detection frequency of DP in dissolved phase in seawater was $<13.1 \%$. Hence, concentrations of syn-DP, anti-DP, and DP in particulate phase could mainly represented for levels of them in water samples. Table 1 and Table S5 summarized the syn-DP, anti-DP, and DP concentrations in river and marine samples. DP were ubiquitous in river samples, with detection frequencies of $100 \%$ both in sediment and water samples. For river samples (Fig. 2), DP concentrations ranged from 46.4 to $165,000 \mathrm{pg} \mathrm{L}^{-1}$ and from 0.65 to $565 \mathrm{pg} \mathrm{g}^{-1} \mathrm{dw}$ in water and sediment, respectively. In comparison, DP concentrations in 22 of 33 river water samples 
Table 1

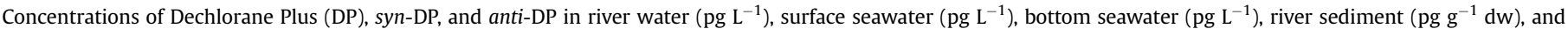
marine sediment ( $\mathrm{pg} \mathrm{g}^{-1} \mathrm{dw}$ ).

\begin{tabular}{|c|c|c|c|c|c|c|}
\hline \multirow[t]{2}{*}{ Compounds } & & \multicolumn{2}{|c|}{ Rivers around Bohai Sea } & \multicolumn{3}{|l|}{ Bohai Sea } \\
\hline & & water & sediment & surface water & bottom water & Sediment \\
\hline \multirow[t]{2}{*}{ syn-DP } & mean & 8500 & 27.8 & 3.31 & 8.64 & 5.31 \\
\hline & range & $25.8-88,700$ & n.d. -142 & n.d. -20.9 & n.d. -84.0 & n.d. -69.9 \\
\hline \multirow[t]{2}{*}{ anti-DP } & mean & 7320 & 48.1 & 4.27 & 13.5 & 14.4 \\
\hline & range & $20.6-76,100$ & $0.65-423$ & n.d. -23.8 & n.d. -153 & n.d. -194 \\
\hline \multirow[t]{2}{*}{ DP } & mean & 15,800 & 75.9 & 7.58 & 22.2 & 19.7 \\
\hline & range & $46.4-165,000$ & $0.65-565$ & n.d. -33.7 & n.d. -274 & n.d. -230 \\
\hline
\end{tabular}
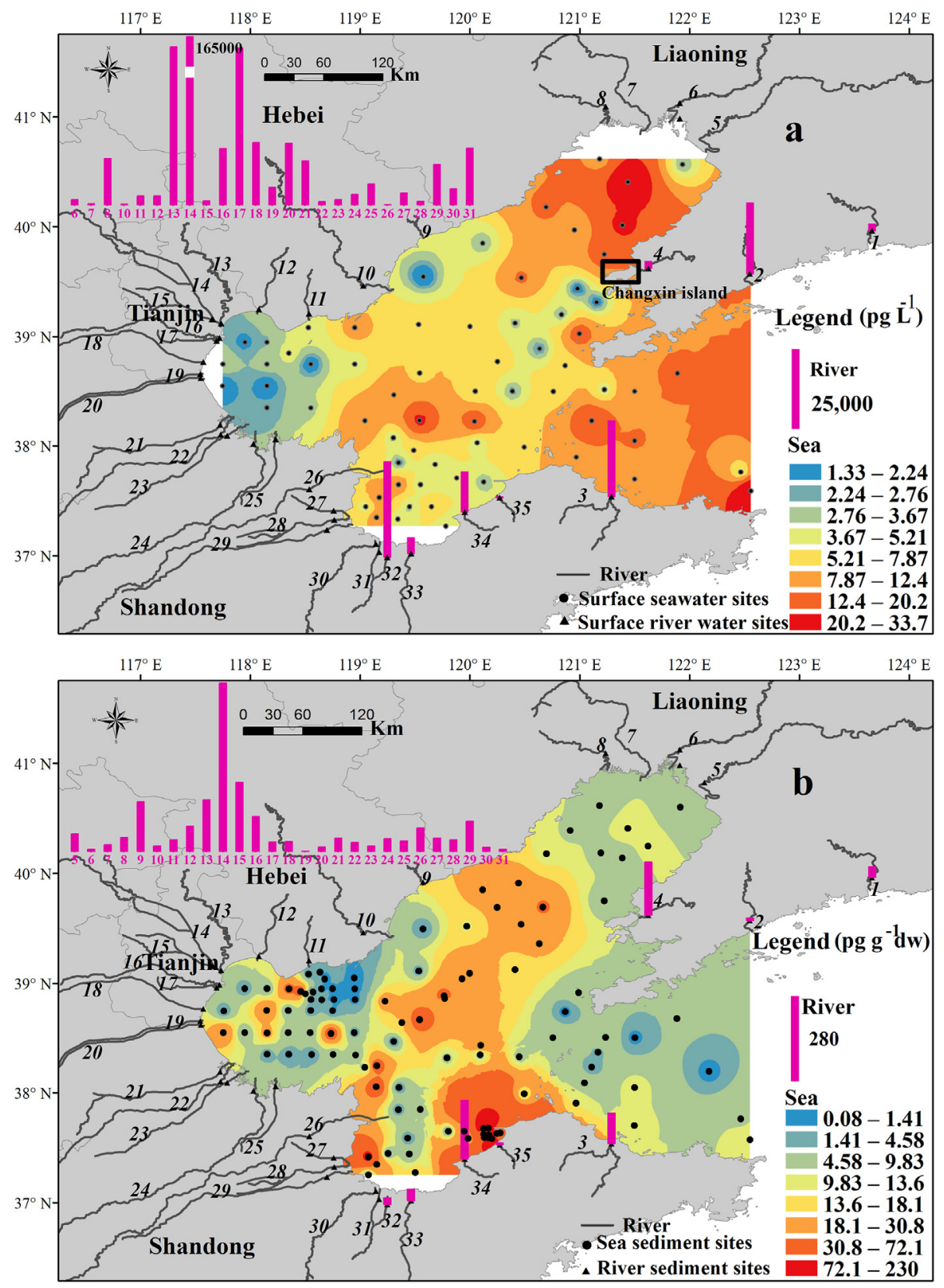

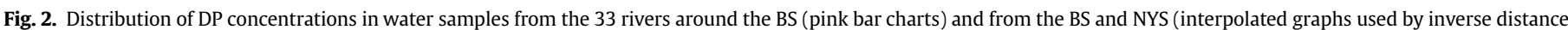

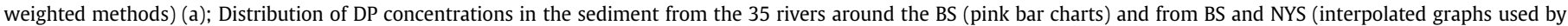
inverse distance weighted methods) (b). (For interpretation of the references to colour in this figure legend, the reader is referred to the Web version of this article.)

(>2850 $\mathrm{pg} \mathrm{L}^{-1}$ ) in present study were higher than those of previously investigated surficial fresh water samples, such as $390 \mathrm{pg} \mathrm{L}^{-1}$ for the Dongjiang River running through a highly industrialized region of southern China (He et al., 2014), $1030 \mathrm{pg} \mathrm{L}^{-1}$ for the 
Chenab River in a highly populated region of Pakistan (Mahmood et al., 2015), and $2440 \mathrm{pg} \mathrm{L}^{-1}$ for an urban watershed in Singapore (Wang and Kelly, 2017). Furthermore, DP concentration for the Xiaoqing River $\left(12,900 \mathrm{pg} \mathrm{L}^{-1}\right)$ in present study was similar to that obtained in our previous study of brominated flame retardants (BFRs) in same area in 2014 (Zhen et al., 2018). DP in river water in the North China was at a high level globally. However, for river sediments (Fig. 2b), DP concentrations in 34 of 35 rivers in this study $\left(<231 \mathrm{pg} \mathrm{L}^{-1}\right)$ were much lower than those in the Jiulong River Estuary (17,500 $\mathrm{pg} \mathrm{g}^{-1} \mathrm{dw}$ ) (Chen et al., 2018), the Yangtze River (1850 $\mathrm{pg} \mathrm{g}^{-1} \mathrm{dw}$ ) (Zhu et al., 2013), the Dongjiang River (2900 pg g $^{-1} \mathrm{dw}$ ) (He et al., 2014), and the Chenab River in Pakistan(1850 pg g $^{-1} \mathrm{dw}$ ) (Mahmood et al., 2015).

In terms of marine samples, DP concentrations was detected in both water and sediment, with detection frequencies of $90 \%$ and $86 \%$, respectively. DP concentrations ranged from n. d. to $33.7 \mathrm{pg} \mathrm{L}^{-1}$, from n. d. to $274 \mathrm{pg} \mathrm{L}^{-1}$, and from n. d. to $230 \mathrm{pg} \mathrm{g}^{-1} \mathrm{dw}$ in surface water, bottom water, and sediment, respectively. DP concentrations in the surface and bottom water samples were 3-4 orders of magnitude lower than that in river water samples. However, DP concentrations in seawater were higher than those reported in seawater samples from the East Asia to the Arctic (0.006-0.40 $\mathrm{pg} \mathrm{L}^{-1}$ ) (Moller et al., 2011) and from the Arctic to Antarctic (n.d. $-1.30 \mathrm{pg} \mathrm{L}^{-1}$ ) (Moller et al., 2010). Mean DP concentrations from the present study were lower than those measured in seawater in other studies, such as King's Bay (93.0 $\mathrm{pg} \mathrm{L}^{-1}$ ) in the Arctic (Na et al., 2015) and the shore around Dalian (1740 $\mathrm{pg} \mathrm{L}^{-1}$ ), northern China (Jia et al., 2011). For sediments, the mean DP concentrations in the BS was 1-2 orders of magnitude lower than those reported in the coastal area around Dalian (2900 $\mathrm{pg} \mathrm{g}^{-1} \mathrm{dw}$ ) (Jia et al., 2011), in Mirs Bay (1070 $\mathrm{pg} \mathrm{g}^{-1} \mathrm{dw}$ ) (Zhu et al., 2018), in King's Bay (343 pg g $^{-1} \mathrm{dw}$ ) (Na et al., 2015), in Pohang Bay (270 $\mathrm{pg} \mathrm{g}^{-1} \mathrm{dw}$ ) (Fang et al., 2014), and in the Yangtze River Delta (330 pg g $^{-1} \mathrm{dw}$ ) (Zhu et al., 2013). In conclusion, DP concentration in the BS was at a low level in the world.

As discussed earlier, river water around the BS were the most heavily contaminated by DP compared with global sites. In fact, we had also analyzed decabromodiphenyl ether (BDE 209) in the same batch of river and marine samples (Zhen et al., 2020). DP concentrations had exceeded BDE 209 concentrations in 23 of 33 river water samples, which was different from a previous study (Li et al., 2018). Commercial deca-BDE was officially banned in many countries since 2008 and had proposed to be listed inAnnexes A, Band/or C of the Stockholm Convention in 2013 (Chen et al., 2020). Meanwhile, the total production amount of decaBDE was decreased. Malak et al. (2018) suggested that the two DP isomers were workable alternatives for deca-BDE owing to the latter being listed as a POPs. Although the recent production data of DP is not available in China, He et al. (2014) had demonstrated that DP contamination in the Pearl River Delta had increased in recent years. Thus, high river water DP levels might reflect huge usage of DP in this area in recent years.

DP concentrations in the river sediments and marine samples (including seawater and sea sediment) were both at low levels. It is coincided with many previous studies in China (Liu et al., 2014; Zhao et al., 2011). Besides, BDE 209 concentrations were higher than DP concentrations in 22 of 33 river sediment samples. Sediment samples could reflect contaminant status over many years. Deca-BDE is the most widely used commercial additive in the polymer industry in China and its estimated annual production was more than 13,000 ton/yr in China before 2018 (Chen et al., 2020; Zhao et al., 2013). For DP, it was 300-1000 ton since 2003 and was manufactured in the East China (Jiangsu province) (Wang et al., 2016). Zhao et al. (2011) had investigated the DP in sediment along coastal area in the Yellow Sea, which suggested that the levels of DP in sediment was also low and its contamination characteristic in this area might not manifest evidence of its source. In addition, DP and BDE 209 had similar physico-chemical properties, which were both tend to adsorbed in particulate phase and then deposited into sediment (Dugani, 2003;Wang et al., 2016). Hence, the low levels of DP in river sediment and marine samples might be mainly ascribed to the low historical annual production and usage of DP in North China compared with BDE 209.

\subsection{Distribution of DP and its influencing factors}

For river water, 14 of the 33 rivers (Fig. 2a and Table S5) had DP concentrations of more than $12,000 \mathrm{pg} \mathrm{L}^{-1}$, seven of which (Chaobai River, Hai River, Dagupaiwu River, Yihui River, Xiaoqing River, Bailang River, and Yu River) are mostly polluted by urban sewage and industrial waste water (Wang et al., 2015); the remaining seven also flow through urban areas. The downstream reaches of the Daling River, Luan River, Yellow River, and Jie River are located in rural areas, and exhibited the lowest DP levels in the study region. In terms of river sediment, the Chaobai River, Hai River, and Xiaoqing River also had relatively higher DP concentrations. For further identification of the factors of DP distribution in river, rivers emptying into the BS were also divided into four sections according to provinces: Liaoning (RLN), Hebei (RHB), Tianjin (RTJ), and Shandong (RSD). Mean DP concentrations in river water, in descending order, were as follows: RTJ $\left(43,700 \mathrm{pg} \mathrm{L}^{-1}\right)>\mathrm{RSD}$ $\left(9020 \mathrm{pg} \mathrm{L}^{-1}\right)>\operatorname{RHB}\left(7580 \mathrm{pg} \mathrm{L}^{-1}\right)>\operatorname{RLN}\left(4790 \mathrm{pg} \mathrm{L}^{-1}\right)$ (Figure S2). According to the Statistics (2010), population density for Tianjin (1080 inhabitants $\mathrm{km}^{-2}$ ), Shandong (647 inhabitants $\mathrm{km}^{-2}$ ), Hebei (381 inhabitants $\mathrm{km}^{-2}$ ) and Liaoning (277 inhabitants $\mathrm{km}^{-2}$ ) was shaped in accordance with the DP distribution in the RTJ, the RSD, the RHB, and the RLN, respectively. Besides, when the logarithm of DP concentrations in great river (GR: annual runoff $(\mathrm{Qi})>1.22 \times 10$ ${ }^{8} \mathrm{~m}^{3}$, Table S2) water were plotted against the logarithm of populations (Table S6; Figure S3), a good correlation $(\mathrm{R}=0.57, \mathrm{P}<0.01$, $\mathrm{N}=26$ ) was obtained. Ren et al. (2008) also found a good correlation between airborne DP concentration and the population. In addition, the largest e-waste dismantling base in North China is located in Tianjin (Lin et al., 2013). Recycling of e-wastes might release high DP into the adjacent environments (Wang et al., 2016). There are both located in the upstream of Chaobai River and Jiyun River, respectively (LTD, 2020a;LTD, 2020b). Chaobai River was also flowing through Beijing, which might be seriously affected by sewage from surrounding urban area. Meanwhile, Chaobai River and Jiyun River had the two top DP concentrations. Wang et al. (2010b) had also reported that the emission of urban activities of use and disposal of products containing DP affected the DP distribution in the environment. Excluding population and emission of e-waste dismantling sites, POC/SPM of SPM in river water had a significant spearman positive correlation with DP concentration ( $\mathrm{p}<0.01, \mathrm{R}=0.54$ ), suggesting a strong impact of environmental parameter on the distribution of DP. Besides, sedimentary TOC also played significant positive correlation with DP concentrations in river sediment (Table S6). It indicated that high TOC and POC/SPM might promote the accumulation of DP in river sediment and river water, respectively.

For marine sediments, relatively high DP concentrations were observed along the Longkou coast (east coast of Laizhou Bay; Fig. 2b). Firstly, this region is close to Longkou, a rapidly expanding industrial city with a population density of 764 inhabitants $\mathrm{km}^{-2}$. Besides, chemical, textile, and building materials are the main industries in Longkou (Wang et al., 2017a). Sverko et al. (2008) had reported that observed $f_{\text {syn }}$ profiles could supply crucial source information. The Wanghe River, which runs through Longkou city before discharging into Laizhou Bay, had similar $f_{\text {syn }}$ values in the 


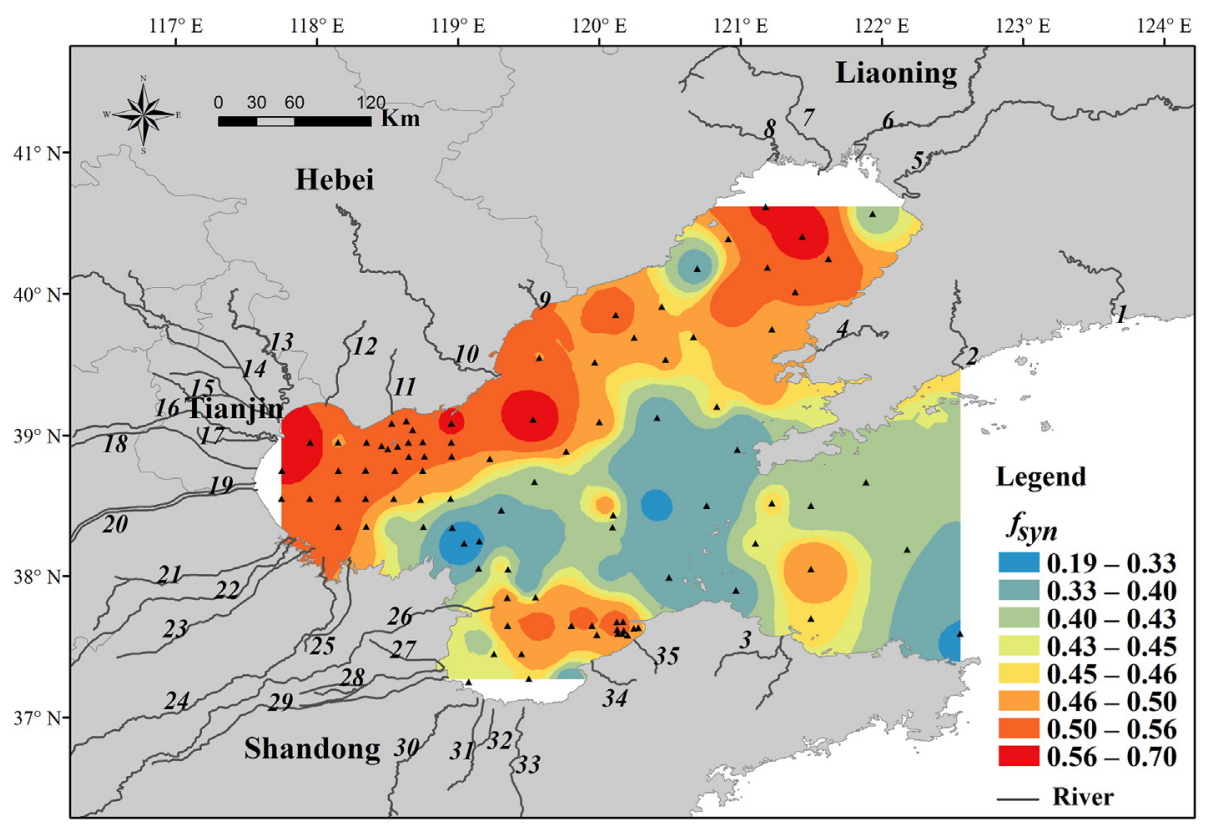

Fig. 3. The $f_{\text {syn }}$ values of DP distribution in surface seawater of the BS.

sediment (0.35) to those in sediments along the Longkou coast (0.20) (Fig. 3). In addition, Fig. 2b showed high DP concentrations were measured in sediment along the west of Laizhou Bay $\left(f_{\text {syn }}\right.$ value of 0.19 , Fig. 3), which were corresponding to high DPs in the nearby rivers (Zimai and Xiaoqing rivers, with $f_{\text {syn }}$ values of 0.38 and 0.26 , respectively). Therefore, emissions from river estuaries may contribute to the high DP distribution in this region. As showed in Fig. 2a and Figure S4c, high DP was observed in surface and bottom seawater at site J51; the Changxindao Island Industry, a national petrochemical base, is close to this site. Jia et al. (2011) also reported high DP concentrations at site $\mathrm{R} 02$, close to site J51. It suggested coastal industrial emission might be another important source of DP. Fig. 2b shows that sedimentary DP levels in the central of BS (CBS) were high. For bottom and surface seawater samples, high DP concentrations were also found around the CBS (Figure S4c and Fig. 2b). Sverko et al. (2008) reported the highest DP level was associated with fine grained sediments in the three depositional basins, suggesting that sill zones are characterized by coarse sediments that absorb DP less effectively than fine silts and clays. Previous study had reported that grain-size scales of sand, silt, and clay are $2000 \mu \mathrm{m}(<1 \Phi)-62.5 \mu \mathrm{m}(4 \Phi), 62.5 \mu \mathrm{m}(4 \Phi)-3.91 \mu \mathrm{m}(8$ $\Phi)$, and $<3.91 \mu \mathrm{m}(>8 \Phi)$, respectively (Yuan et al., 2020). Therefore, the grain - size of sediments in the CBS area ranged from 4.11 to 7.02 $\Phi$ (median value: $6.08 \Phi$ ) (Fang et al., 2015), which is belongs to fine silts. Hu et al. (2009) also reported high DDTs concentrations around the same area of the BS. Furthermore, a previous study found high levels of HFRs distributed in the depositional zones of the Yellow Sea (YS) (Li et al., 2019). Sediments collected from the Longkou coast and west of Laizhou Bay are also belong to fine silts (4.3-5.5 $\Phi)$ (Fig. 4a). Figure S4b shows that the Yellow River Estuary (YRE) had relatively high SPM which was deposited in summer. From winter to spring, suspended sediments were redistributed in the BS as a result of active coastal resuspension and transport along the Longkou coast and southern Bohai Strait to the YS by way of coastal circulation (Wang et al., 2014). Furthermore, the $f_{\text {syn }}$ value in the YRE (0.27) was similar to that for the Longkou coast. Hence, the distribution of DP in the BS was controlled by multiple factors, including anthropogenic activities, hydrodynamic conditions, and sedimentary features.

\subsection{Fractional abundances of DP isomers}

As shown in Figure $\mathrm{S} 1$, the mean $f_{\text {syn }}$ values in river water was the highest $(0.53 \pm 0.04)$, followed by that in surface seawater $(0.45 \pm 0.10)$, bottom seawater $(0.44 \pm 0.11)$, river sediment $(0.41 \pm 0.13)$, and sea sediment $(0.25 \pm 0.18)$. Previous studies had also reported that relatively high $f_{\text {syn }}$ values in river water were seriously affected by urban and industrialized production, such as 0.71 for the Chenab River in Pakistan (Mahmood et al., 2015), 0.61 for an urban watershed in Singapore (Wang and Kelly, 2017), and 0.57 for the Xiaoqing River in China (Zhen et al., 2018). Jia et al. (2011) reported $f_{\text {syn }}$ values for technical DP products ranged from 0.20 to 0.36 , and $f_{\text {syn }}$ value of 0.41 for commercial DP products in China. $f_{\text {syn }}$ values in 15 out of 35 river sediments in this study were comparable to that of technical DP products, indicating that these rivers might be affected by direct emissions of technical DP products. The lowest mean $f_{\text {syn }}$ value was occurred in sea sediments, with values consistent with those in sediments for the Pearl River Estuary (0.25) (Sun et al., 2016), Jiaozhou Bay (0.29) (Zhao et al., 2011), and Dongjiang River (0.23) (He et al., 2014).

The significance $f_{\text {syn }}$ value in five environmental media was that $f_{\text {syn }}$ values in water (including river water and sea water) were higher than those in sediment (including river sediment and sea sediment). Firstly, stability of syn-DP in water was higher than that of anti-DP in terms of photodegradation (Sverko., 2008; Wang et al., 2010b; Wang and Kelly, 2017; Zhen et al., 2018). Secondly, Fang et al. (2014)demonstrated that the enrichment of anti-DP over syn-DP could be attributed to higher sorption of anti-DP by sediment and/or by preferential biodegradation of syn-DP in sediment. Sedimentary TOC could influence the accumulation of POPs because of their high affinity (Wang et al., 2017b). In this study, anti-DP concentration in river sediment showed stronger positive correlations with sedimentary TOC than syn-DP concentration (Table S7), indicating higher accumulation of anti-DP in sediment compared to syn-DP. In addition, dissolved syn-DP concentration was all higher than anti-DP concentration in river water (Table S5). Previous study suggested that syn-DP had higher tendency to transform into bioavailable fraction, which caused the $f_{\text {syn }}$ values for bound-residue DP decreased from 0.25 to 0.15 in soil (Cheng et al., 


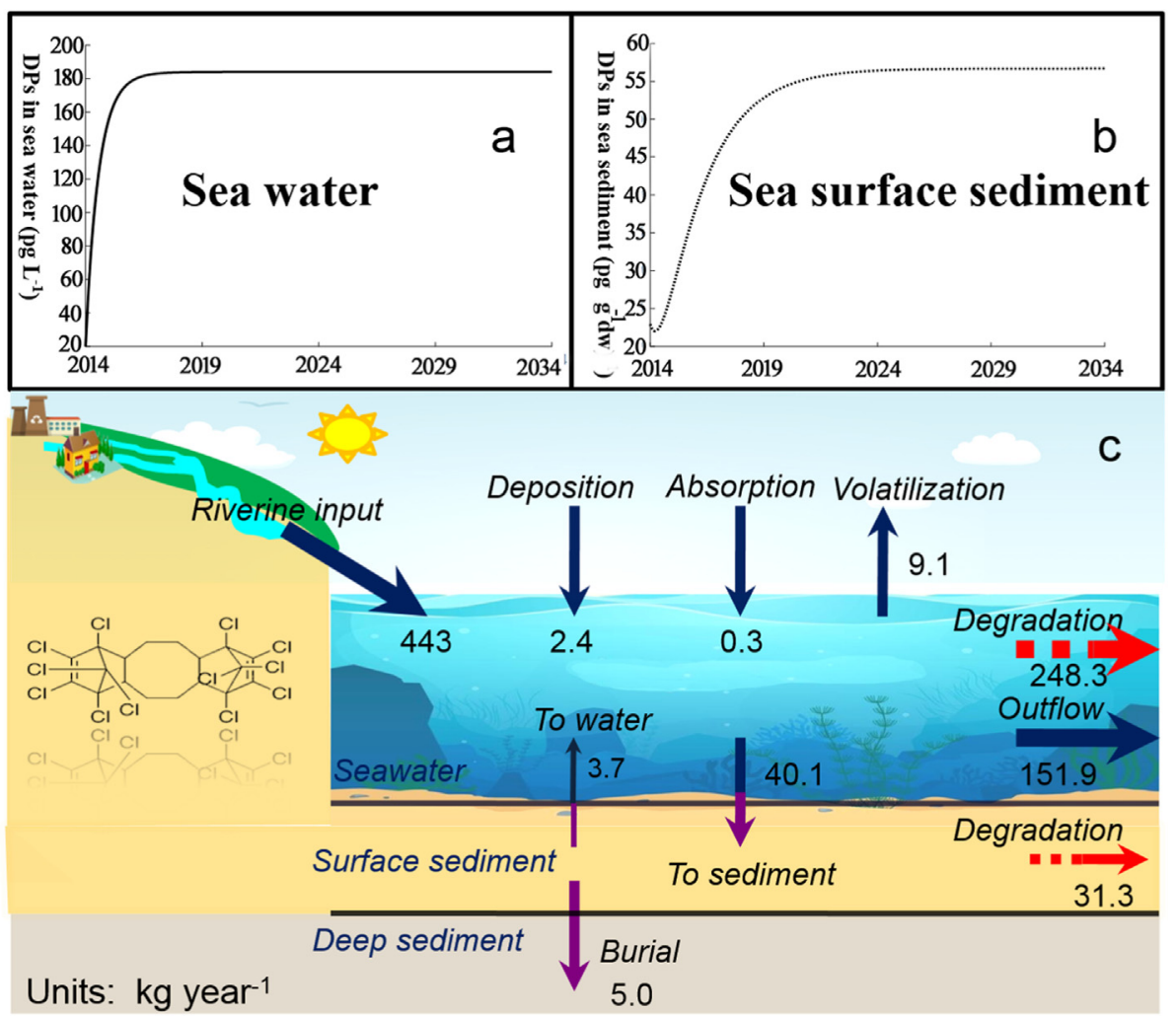

Fig. 4. Estimation of DP concentrations in seawater (a) and sediment (b) of the BS over the time, and mass balance for DP in the steady-state case in the BS (c).

2020). Hence, syn-DP was depleted faster than anti-DP in sediment. For aquatic environments, $f_{\text {syn }}$ value showed a decreasing trend from the river water to the seawater and same trend from inshore to offshore (Fig. 3), possibly indicating selective biodegradation and bioaccumulation of syn-DP and/or preferential deposition of antiDP during water transport.

\subsection{Fluxes and multi-box mass balance model of DP in the BS}

\subsubsection{DP river flux into the $B S$}

The DP riverine inputs of 30 rivers discharging into the BS were shown in Table S2; values ranged from 0.02 to $247 \mathrm{~kg} \mathrm{yr}^{-1}$, with an average of $14.8 \mathrm{~kg} \mathrm{yr}^{-1}$. The total riverine input of DP into the BS was calculated to be $\sim 443 \mathrm{~kg} \mathrm{yr}^{-1}$. For the subregions, DP flux of RTJ was $377 \mathrm{~kg} \mathrm{yr}^{-1}$, accounting for $85 \%$ of the total DP river flux into the BS (Table S2). It suggested that DP river flux from RTJ dominated the total river loading into the BS. Similar to the distribution of DP level, the highest DP river flux $\left(247 \mathrm{~kg} \mathrm{yr}^{-1}\right)$ also occurred in Chaobai River. Besides, Jiyun River, Dagupaiwu River, and Duliujian River were all higher than $15 \mathrm{~kg} \mathrm{yr}^{-1}$, which were corresponding to their relative high DP concentrations and moderate river runoffs (Figure S5). Thus, these four rivers with the top four river fluxes were mainly affected by high DP concentrations owing to urbanization level and emission of e-waste discussed above. However, Liao River had relatively low DP concentration and the second largest river runoff, with the fifth highest DP river flux. Thus, river with huge runoff, also could play an important role in delivering DP into the BS. Pollutant concentrations and river runoff remain the two controlling factors for evaluating the contribution of river discharge.
3.4.2. Time-dependent DP concentration and budget using the multi-box mass balance model

DP concentrations in river water, river sediment, sea water, and sea sediment were measured between 2013 and 2014 (Table S5). As showed in Fig. 4a, simulated seawater DP concentrations increased until reaching a plateau $\left(\mathrm{dM} / \mathrm{dt} \leq-10^{-5}\right)$ after nearly $11 \mathrm{yrs}$, assuming a constant input of DP to the BS. DP concentrations increased rapidly in the first year and then leveled off at $\sim 184 \mathrm{pg} \mathrm{L}^{-1}$ (Fig. 4a). Wang et al. (2016b) summarized that DP contamination in the environment was largely affected by nearby emissions. When reducing the riverine inputs to $0.16 \mathrm{~kg} \mathrm{yr}^{-1}$ (data was unpublished and was obtained in 2018-2019 in our later work) after 2013, resulted in the decrease of water and sediment of DP by keeping constant parameters used in the multi-box mass balance model (Figure S6). In 2017, the estimation DP concentration in seawater in the BS was about $1.26 \mathrm{pg} \mathrm{L}^{-1}$, which was comparable to $1.09 \mathrm{pg} \mathrm{L}^{-1}$ in surface seawater in 2016-2017 in BS (Liu et al., 2020). Thus, the result suggested that the measured DP concentrations were well estimated by model. Hence, the riverine input of DP had a great influence in DP levels in seawater. As for sediment, DP reached this steady-state after approximately 17 yrs (Fig. 4b). By then, initial DP concentration had been increased to $56.7 \mathrm{pg} \mathrm{g}^{-1} \mathrm{dw}$.

In the steady-state scenario for water (Fig. 4c), tributary loadings of DP to BS were $443 \mathrm{~kg} \mathrm{yr}^{-1}$, in addition to $3.7 \mathrm{~kg} \mathrm{yr}^{-1}$ from the sediment (sum of resuspension and diffusion), and $2.7 \mathrm{~kg} \mathrm{yr}^{-1}$ from the atmosphere (including wet deposition, dry deposition, and absorption) (SI Table S3, SI equation 12) (Liu et al., 2020). The riverine discharge of DP dominated $~ 99 \%$ of the total loading. Zhen et al. (2018) found that discharge of the Xiaoqing River affected the DP distribution in water samples from the Laizhou Bay in the BS. Sverko et al. (2008) suggested that the observed similarity of $f_{\text {syn }}$ profiles between Lake Ontario and the Niagara River indicated that river is a major source of Lake Ontario's DP burden. Such a similarity 
was also found between $f_{\text {syn }}$ values for rivers and the sea in the present study (section 3.3). Besides, the $f_{\text {syn }}$ value in the atmosphere (0.22) was much lower than that in seawater of the BS (Liu et al., 2020). Hence, river discharge was a significant source of DP in the BS. In terms of outputs, the degradation, outflow, water to sediment transport (including sedimentation and diffusion) and volatilization accounted for $55.3 \%, 33.8 \%, 8.92 \%$, and $2.02 \%$ of the total DP influx, respectively. This finding differs from previous outputs of black carbon (BC) and heavy metal in the BS revealing the absolutely dominant role of sedimentation (Fang et al., 2015; Liang et al., 2018). DP were relative persistence in the environment (Cheng et al., 2019; Huang et al., 2020). However, previous study had also found dechlorination (DP $[-\mathrm{Cl}+\mathrm{H}]$ and $[-2 \mathrm{Cl}+2 \mathrm{H}]$ degradation products) and other unidentified DP-degradation products by photodegradation (Canada, 2019). Besides, biodegradation modelling identified three low probability products of parent DP $\left(\mathrm{C}_{18} \mathrm{H}_{13} \mathrm{Cl}_{11} \mathrm{O}_{1}, \mathrm{C}_{18} \mathrm{H}_{12} \mathrm{Cl}_{10} \mathrm{O}_{1}\right.$, and $\left.\mathrm{C}_{18} \mathrm{H}_{12} \mathrm{Cl}_{10} \mathrm{O}_{2}\right)$ (Canada, 2019). However, the main degradation product of DP is still not reported in the world. Microbial degradation accounted for $8.33 \%-54.1 \%$ of total DP dissipation in planted soil and the half-life of DP in the rhizosphere is $105 \mathrm{~d}$ (Cheng et al., 2020). A decrease in parent DP concentration of $10 \%$ at $168 \mathrm{~h}$ and a further loss of $40 \%$ at $264 \mathrm{~h}$ and $65 \%$ at $504 \mathrm{~h}$ were observed by Sverko et al. (2008). In this paper, DP concentrations in surface seawater and sediment during 2013-2014 were both 2-3 orders of magnitude lower than those in similar sites collected from the coast of Liaodong Bay in 2008 (Jia et al., 2011). In fact, the relatively long half-lives in water and sediment were adopted in the present study (Canada, 2019). The evidence suggested that degradation is a major factor governing DP output though they are persistent environmental pollutants. For outflow, DP is easily absorbed onto fine particles. Net particles are transported from the BS to the YS through the southern channel of the Bohai Strait. Fang et al. (2015) also suggested that export to the YS was an important BS BC outlet. In present study, the $f_{\text {syn }}$ value showed decrease trend from the river water to seawater, suggested the degradation of DP was occurred. In the steady-state scenario in sediment (Fig. 4c), water to sediment (including sedimentation and diffusion) was the major input flux, while degradation and burial to deep sediment were two major outlets, with contributions of $78.1 \%$ and $12.5 \%$, respectively.

\section{Conclusion}

This study conducted the first overview of DP distribution, isomers, fluxes, and budget in the BS. The high DP contaminations were found in 33 river estuaries across more than $2668 \mathrm{~km}$ of China's coastline. This paper provided regional scale evidences that DP in river estuary was affected by urbanization and emission of Ewaste. The spatial distribution of DP was impacted by terrigenous input and hydrodynamic conditions. The $f_{\text {syn }}$ value in various environmental components suggested the stereoselective degradation of DP during sedimentation and water transport. Total riverine DP input into the BS was $443 \mathrm{~kg} \mathrm{yr}^{-1}$, accounting for $~ 99 \%$ of the total input of DP into the BS, which dominated the level of DP in the BS. We estimated the budget of DP in a steady-state scenario for water and sediment by combining real DP data and a multi-box mass balance model. The results indicated that degradation and outflow to the YS are two major outlets for DP in seawater. For sediments, burial to deep sediment and degradation are two major outlets for DP. It is note-worthy that there was inherent uncertainty in the estimation of DP concentrations and DP degradation contribution in actual environment resulting from lack of field measured values of half-life times of DP in actual environment and continuous measured field data in various environment component. This suggested that we should be more focus on more field data to refine the model. However, this study also provided a new method to estimate DP concentration and apportion DP outlets based on a model in a typical semi-closed sea that will be meaningful in further studies.

\section{Declaration of competing interest}

The authors declare that they have no known competing financial interests or personal relationships that could have appeared to influence the work reported in this paper.

\section{Acknowledgement}

This study was supported by the National Natural Science Foundation of China (No. U1806207 and 41773138), the key project of Chinese Academy of Sciences (XDA11020402 and KFJ-STS-QYZX057), key deployment project of Centre for Ocean Mega-Science, Chinese Academy of Sciences (COMS2019J08) and by the seed project of Yantai Institute of Coastal Zone Research, Chinese Academy of Sciences (No. YIC Y855011024).

\section{Appendix A. Supplementary data}

Supplementary data to this article can be found online at https://doi.org/10.1016/j.envpol.2020.116214.

\section{References}

Canada, E., 2019. Screening assessment certain organic flame retardants substance grouping. https://www.canada.ca/en.html.

Chen, X., Zhu, Y. Huang, O. Liu, J., Liu, B., Zhang, Y., 2018. Distributions, influencing factors, and risk assessment of Dechlorane Plus and related compounds in surficial water and sediment from the Jiulong River Estuary, Southeast China. Environ. Sci. Pollut. Control Ser. 25, 30292-30300.

Chen, Y., Li, J., Tan, Q., 2020. Trends of production, consumption and environmental emissions of Decabromodiphenyl ether in mainland China. Environ. Pollut. 260, 114022.

Cheng, Y., Ding, J., Xie, X., Ji, X., Zhang, Y., 2019. Validation and application of a 3 step sequential extraction method to investigate the fraction transformation of organic pollutants in aging soils: a case study of dechlorane plus. Environ. Sci. Technol. 53, 1325-1333.

Cheng, Y., Ding, J., Liang, X., Ji, X., Xu, L., Xie, X., Zhang, Y.K., 2020. Fractions transformation and dissipation mechanism of dechlorane plus in the rhizosphere of the soil-plant system. Environ. Sci. Technol. 54, 6610-6620.

Dugani, F.W.a.C.B., 2003. Assessing the long-range transport potential of polybrominated diphenyl ethers: a comparison of four multimedia models. Environ. Toxicol. Chem. 22, 1252-1261.

Fang, M., Kim, J.C., Chang, Y.S., 2014. Investigating Dechlorane Plus (DP) distribution and isomer specific adsorption behavior in size fractionated marine sediments. Sci. Total Environ. 481, 114-120.

Fang, Y., Chen, Y., Tian, C., Lin, T., Hu, L., Huang, G., Tang, J., Li, J., Zhang, G., 2015. Flux and budget of $\mathrm{BC}$ in the continental shelf seas adjacent to Chinese high BC emission source regions. Global Biogeochem. Cycles 29, 957-972.

He, M., Luo, X., Wu, J., Chen, S., Wei, S., Mai, B., 2014. Isomers of Dechlorane Plus in an aquatic environment in a highly industrialized area in Southern China: spatial and vertical distribution, phase partition, and bioaccumulation. Sci. Total Environ. 481, 1-6.

Hu, L., Zhang, G., Zheng, B., Qin, Y., Lin, T., Guo, Z., 2009. Occurrence and distribution of organochlorine pesticides (OCPs) in surface sediments of the Bohai Sea, China. Chemosphere 77, 663-672.

Huang, G., 2016. The Spatial-Temporal Vairations of Dissolved Black Carbon in the the Bohai Sea Water, China and the River Fluxes Yantai Institute of Coastal Zone Research,Chinese Academy of Sciences. Chinese Academy of Sciences. Yantai Institute of Coastal Zone Research,Chinese Academy of Sciences.

Huang, H., Li, J., Zhang, Y., Chen, W., Ding, Y., Chen, W., Qi, S., 2020. How persistent are POPs in remote areas? A case study of DDT degradation in the Qinghai-Tibet Plateau, China. Environ. Pollut. 263, 114574.

Jia, H., Sun, Y., Liu, X., Yang, M., Wang, D., Qi, H., Shen, L., Sverko, E., Reiner, E.J., Li, Y.F., 2011. Concentration and bioaccumulation of dechlorane compounds in coastal environment of northern China. Environ. Sci. Technol. 45, 2613-2618.

Li, B., Wang, K., Ma, L.X., Sun, S.J., Jia, L.R., Yuan, A.N., Shen, J.M., Qi, H., Zhang, A.P., 2018. Deca-BDE and alternative halogenated flame retardants in a wastewater treatment plant in Harbin (2009-2016): occurrence, temporal trends, seasonal variation, and fate. Sci. Total Environ. 625, 1156-1163.

Li, Y., Zhen, X., Liu, L., Tian, C., Pan, X., Tang, J., 2019. Halogenated flame retardants in the sediments of the Chinese Yellow Sea and east China sea. Chemosphere 234, 
$365-372$.

Liang, X., Tian, C., Zong, Z., Wang, X., Jiang, W., Chen, Y., Ma, J., Luo, Y., Li, J., Zhang, G., 2018. Flux and source-sink relationship of heavy metals and arsenic in the Bohai Sea, China. Environ. Pollut. 242, 1353-1361.

Lin, Y., Qiu, X., Zhao, Y., Ma, J., Yang, Q., Zhu, T., 2013. Polybromobenzene pollutants in the atmosphere of North China: levels, distribution, and sources. Environ. Sci. Technol. 47, 12761-12767.

Liu, H.H., Hu, Y.J., Luo, P., Bao, L.J., Qiu, J.W., Leung, K.M., Zeng, E.Y., 2014. Occurrence of halogenated flame retardants in sediment off an urbanized coastal zone: association with urbanization and industrialization. Environ. Sci. Technol. 48, 8465-8473.

Liu, Q., Guo, X., Yin, Z., Zhou, K., Roberts, E., Dai, M., 2018. Carbon fluxes in the China Seas: an overview and perspective. Sci. China Earth Sci. 61, 1564-1582.

Liu, L., Zhen, X., Wang, X., Li, Y., Sun, X., Tang, J., 2020. Legacy and novel halogenated flame retardants in seawater and atmosphere of the Bohai Sea: spatial trends, seasonal variations, and influencing factors. Water Res. 184, 116117.

LTD, T.H., 2020a. Tianjin Hechang Environmental Protection Technology Co. LTD. http://1696234.b2b.tfsb.cn/.

LTD, T.T., 2020b. Taiding (Tianjin). Environmental Protection Technology Co. LTD. http://www.tdtj.com.cn/.

Mackay, D., Sang, S., Vlahos, P., Gobas, F., Diamond, M., Dolan, D., 1994. A rate constant model of chemical dynamics in a lake ecosystem: PCBs in Lake Ontario. J. Great Lake. Res. 20, 625-642.

Mahmood, A., Malik, R.N., Li, J., Zhang, G., 2015. Distribution, congener profile, and risk of polybrominated diphenyl ethers and dechlorane plus in water and sediment from two tributaries of the Chenab River, Pakistan. Arch. Environ. Contam. Toxicol. 68, 83-91.

Malak, A.I., Cariou, R., Venisseau, A., Dervilly-Pinel, G., Jaber, F., Babut, M., Le Bizec, B., 2018. Occurrence of Dechlorane Plus and related compounds in catfish (Silurus spp.) from rivers in France. Chemosphere 207, 413-420.

Moller, A., Xie, Z., Sturm, R., Ebinghaus, R., 2010. Large-scale distribution of dechlorane plus in air and seawater from the arctic to Antarctica. Environ. Sci. Technol. 44, 8977-8982.

Moller, A., Xie, Z., Cai, M., Zhong, G., Huang, P., Cai, M., Sturm, R., He, J., Ebinghaus, R., 2011. Polybrominated diphenyl ethers vs alternate brominated flame retardants and Dechloranes from East Asia to the Arctic. Environ. Sci. Technol. 45, 6793-6799.

Na, G., Wei, W., Zhou, S., Gao, H., Ma, X., Qiu, L., Ge, L., Bao, C., Yao, Z., 2015. Distribution characteristics and indicator significance of Dechloranes in multimatrices at Ny-Alesund in the Arctic. Journal of Environmenal Science (China) $28,8-13$.

Qiao, L., Zheng, X.B., Yan, X., Wang, M.H., Zheng, J., Chen, S.J., Yang, Z.Y., Mai, B.X., 2018. Brominated flame retardant (BFRs) and Dechlorane Plus (DP) in paired human serum and segmented hair. Ecotoxicol. Environ. Saf. 147, 803-808.

Ren, N., Sverko, E., Li, Y., Zhang, Z., Harner, T., Wang, D., Wan, X., E mccarry, B., 2008. Levels and isomer profiles of dechlorane plus in Chinese air. Environ. Sci. Technol. 42, 6476-6480.

Sanchez-Soberon, F., Sutton, R., Sedlak, M., Yee, D., Schuhmacher, M., Park, J.S., 2020. Multi-box mass balance model of PFOA and PFOS in different regions of San Francisco Bay. Chemosphere 252, 126454.

Statistics, N.B.o., 2010. Tabulation on the 2010 Population Census of the People Republic of China. http://www.stats.gov.cn/tjsj/pcsj/rkpc/6rp/indexch.htm.

Sun, Y.X., Zhang, Z.W., Xu, X.R., Hao, Q.W., Hu, Y.X., Zheng, X.B., Luo, X.J., Diao, Z.H., Mai, B.X., 2016. Spatial and vertical distribution of dechlorane plus in mangrove sediments of the Pearl River estuary, south China. Arch. Environ. Contam. Toxicol. 71, 359-364.

Sverko, E., Tomy, G., Marvin, C., Zaruk, D., Reiner, E., Helm, P., Hill, B., Mccarry, B., 2008. Dechlorane plus levels in sediment of the lower great lakes. Environ. Sci. Technol. 42, 361-366.
Wang, Q., Kelly, B.C., 2017. Occurrence and distribution of halogenated flame retardants in an urban watershed: comparison to polychlorinated biphenyls and organochlorine pesticides. Environ. Pollut. 231, 252-261.

Wang, B., Iino, F., Huang, J., Lu, Y., Yu, G., Morita, M., 2010a. Dechlorane plus pollution and inventory in soil of huai'an city, China. Chemosphere 80, 1285-1290.

Wang, D., Yang, M., Qi, H., Sverko, E., Ma, W., Li, Y., Alaee, H.E.R., Shen, L., 2010b. An asia-specific source of dechlorane plus: concentration, isomer profiles, and other related compounds. Environ. Sci. Technol. 44, 6608-6613.

Wang, H., Wang, A., Bi, N., Zeng, X., Xiao, H., 2014. Seasonal distribution of suspended sediment in the Bohai Sea, China. Continent. Shelf Res. 90, 17-32.

Wang, R., Tang, J., Huang, G., Chen, Y., Tian, C., Pan, X., Luo, Y., Li, J., Zhang, G., 2015. Provenance of organic matter in estuarine and marine surface sediments around the biahi sea. Ooceanologia Et Limnologia Sinica 46, 497-507.

Wang, G., Peng, J., Hao, T., Liu, Y., Zhang, D., Li, X., 2016a. Distribution and regionspecific sources of Dechlorane Plus in marine sediments from the coastal East China Sea. Sci. Total Environ. 573, 389-396.

Wang, P., Zhang, Q., Zhang, H., Wang, T., Sun, H., Zheng, S., Li, Y., Liang, Y., Jiang, G., 2016b. Sources and environmental behaviors of Dechlorane Plus and related compounds - a review. Environ. Int. 88, 206-220.

Wang, F., Li, C., Wang, J., Cao, W., Wu, Q., 2017a. Concentration estimation of heavy metal in soils from typical sewage irrigation area of Shandong Province, China using reflectance spectroscopy. Environ. Sci. Pollut. Control Ser. 24, 16883-16892.

Wang, G., Peng, J., Hao, T., Feng, L., Liu, Q., Li, X., 2017b. Effects of terrestrial and marine organic matters on deposition of dechlorane plus (DP) in marine sediments from the Southern Yellow Sea, China: evidence from multiple biomarkers. Environ. Pollut. 230, 153-162.

Yuan, P., Wang, H., Wu, X., Bi, N., 2020. Grain-size distribution of surface sediments in the Bohai Sea and the northern Yellow Sea: sediment supply and hydrodynamics. J. Ocean Univ. China 19, 589-600.

Zhao, Z., Zhong, G., Moller, A., Xie, Z., Sturm, R., Ebinghaus, R., Tang, J., Zhang, G., 2011. Levels and distribution of dechlorane plus in coastal sediments of the Yellow Sea, north China. Chemosphere 83, 984-990.

Zhao, Y., Ma, J., Qiu, X., Lin, Y., Yang, Q., Zhu, T., 2013. Gridded field observations of polybrominated diphenyl ethers and decabromodiphenyl ethane in the atmosphere of north China. Environ. Sci. Technol. 47, 8123-8129.

Zhen, X., Tang, J., Xie, Z., Wang, R., Huang, G., Zheng, Q., Zhang, K., Sun, Y., Tian, C., Pan, X., Li, J., Zhang, G., 2016. Polybrominated diphenyl ethers (PBDEs) and alternative brominated flame retardants (aBFRs) in sediments from four bays of the Yellow Sea, North China. Environ. Pollut. 213, 386-394.

Zhen, X., Tang, J., Liu, L., Wang, X., Li, Y., Xie, Z., 2018. From headwaters to estuary: distribution and fate of halogenated flame retardants (HFRs) in a river basin near the largest HFR manufacturing base in China. Sci. Total Environ. 621, 1370-1377.

Zhen, X., Li, Y., Tang, J., Wang, X., Liu, L., Zhong, M., Tian, C., 2020. Legacy and Noval Brominated Flame Retardants (BFRs) in the Bohai Sea, China: Distribution, Budget, and Influencing Factors. Manuscript to be submitted to Environmental Science and Technology (unpublish data).

Zhou, S., Fu, J., He, H., Fu, J., Tang, Q., Dong, M., Pan, Y., Li, A., Liu, W., Zhang, L., 2017. Spatial distribution and implications to sources of halogenated flame retardants in riverine sediments of Taizhou, an intense e-waste recycling area in eastern China. Chemosphere 184, 1202-1208.

Zhu, B., Lam, J.C., Yang, S., Lam, P.K., 2013. Conventional and emerging halogenated flame retardants (HFRs) in sediment of Yangtze River Delta (YRD) region, East China. Chemosphere 93, 555-560.

Zhu, B., Lam, J.C.W., Lam, P.K.S., 2018. Halogenated flame retardants (HFRs) in surface sediment from the Pearl River Delta region and Mirs bay, south China. Mar. Pollut. Bull. 129, 899-904. 